\title{
Fundamentos
}

Resumo
O objetivo deste artigo é discu-
tir alguns dos primeiros estudos
que se voltaram à compreensão
das relações objetais primá-
rias. Para tanto, a atenção se
volta para a chamada Escola
Húngara de Psicanálise, grupo
composto porpsicanalistas das
primeiras gerações do movimen-
to psicanalitico liderado por
Sándor Ferenczi e responsável
por estudos vanguardistas e
bastante originais no que se
refere à teoria psicanalítica
do desenvolvimento subjetivo,
às práticas clinicas e à técnica
psicanalítica. Numa perspec-
tiva histórica, esses estudos
foram pioneiros em considerar
as relações primordiais entre
mãe-bebế - fundamentaram e
influenciaram grandes nomes e
escolas da psicanálise.
Descritores: psicanálise;
história da psicanálise; relações
objetais; Escola Húngara.

\section{A PRIMAZIA DAS RELAÇÕES OBJETAIS NO DESENVOLVIMENTO SUBJETIVO PRESENTE NOS ESTUDOS DA ESCOLA HÚNGARA DE PSICANÁLISE: UMA PERSPECTIVA HISTÓRICA}

A atenção dos psicanalistas da Escola Húngara nos estágios mais primitivos do desenvolvimento infantil levou-os a formular postulações importantes para o desenvolvimento ulterior da psicanálise: influenciaram muitos dos avanços teóricos e técnicos, principalmente os que viriam já num período pós-freudiano. Alice Balint, com seus estudos acerca da relação primária entre mãe e bebê, por exemplo, representaria bem o ideário da Escola - mesmo que limitados quantitativamente devido à morte precoce da psicanalista, esboçavam relevantes contribuições para se pensar o desenvolvimento infantil

- Pós-doutorando na Universidade Federal de Uberlândia (UFU). Doutor em Psicologia pela Universidade Estadual Paulista (UNESP/Assis), Assis, SP, Brasil

- - Professor dos cursos de graduação e pós-graduação em Psicologia na Universidade Estadual Paulista (UNESP/Assis). Assis, SP, Brasil. 
e a educação. A autora, num diálogo constante também com a pedagogia, apresenta pensamentos bastante inovadores - pautados em propostas de Ferenczi e "aprimorados" por outros teóricos - e se pauta bastante em sua prática clínica, característica comum aos estudos húngaros. Ainda que pouco estudada, mesmo nos dias de hoje, é notável a importância que A. Balint teve para a história da psicanálise húngara como membro assíduo da Associação Psicanalítica e presença marcante tanto no Instituto de Formação, como no trabalho com as crianças da Policlínica Psicanalítica de Budapeste.

Alguns de seus textos, traduzidos para outros idiomas, foram publicados postumamente - mas muito nos diriam estes sobre A. Balint como psicanalista ao ressaltarem os maiores pontos de interesse das discussões propostas pela autora. A partir de dois deles, "Identificação" (A. Balint, 1943) e "Amor pela mãe e amor materno" (A. Balint, 1939/1952) apresentaremos pontos essenciais das propostas de A. Balint sobre a compreensão das primeiras relações estabelecidas na vida do sujeito - esses postulados, de certo modo, representariam uma visão compartilhada pela Escola Húngara e iriam influenciar outros teóricos que se voltam aos estudos da psicanálise infantil.

O primeiro desses estudos, "Identificação", foi escrito e publicado originalmente em 1931 - ele já adiantaria alguns pontos teóricos essenciais que seriam apresentados pela autora no outro artigo, "Amor pela mãe e amor materno", publicado em 1939 - ano de sua morte. Em "Identificação", a autora tem como intuito discutir o desenvolvimento infantil considerando a relação da criança com o mundo externo: a "conquista" desse mundo externo, seu desbravamento, a relação estabelecida com o ambiente e com as experiências, enfim, se dariam por meio de uma série de identificações - esse conceito, no entanto, é utilizado num sentido muito mais amplo do que o usual em psicanálise. Para A. Balint, é a partir dessas identificações essencialmente subjetivas de objetos e experiências que poderíamos nos relacionar com o mundo externo.

O escopo do artigo, em última instância, seria o de discutir a educação infantil - A. Balint o faz por meio de observações diretas de crianças e são inúmeros os exemplos que utiliza ao longo do texto para embasar suas ideias. O texto, apesar de se voltar às discussões pertinentes à teoria psicanalítica, tem uma composição essencialmente prática, vivenciada e analisada pela psicanalista. Mesmo que voltado também à pedagogia e à educação, a autora estabelece um debate que antecede tudo: como todos os principais problemas referentes às medidas educativas só ocorrem a partir da relação conflituosa entre o ego e o mundo externo, A. Balint traça uma investigação minuciosa acerca do fenômeno, que irá chamar de pensamento identificatório. Para o nosso estudo, esse é justamente o recorte que mais irá interessar: a discussão teórica acerca do que a autora compreende como identificação, num sentido ampliado, e suas ideias sobre 
a relação entre a criança e o mundo, que antecipam algumas propostas que serão desenvolvidas ulteriormente, também por outros psicanalistas, sobre as relações objetais.

Vale considerar desde o início que A. Balint deixa claro que a identificação, aqui, não se trata ainda de uma relação objetal amorosa - seria mais bem definida como um tipo de incorporação ou assimilação, embora também se caracterize por fornecer algum prazer à criança, além de ajudá-la com a resolução de conflitos. Seria esse o modo pelo qual a criança conhece o mundo externo - a autora sustenta que além da gratificação direta essa seria a única maneira de nos aproximarmos deste mundo externo.

A. Balint vai dizer que a criança começa identificando coisas externas com outras familiares a si, como massas quaisquer com fezes ou líquidos com urina, num primeiro momento. Afirma que o vantajoso nesse processo é a possibilidade que a criança teria de encontrar substitutos para suas primeiras fontes de prazer que, aos poucos, vão sendo renunciadas graças à imposição da educação. $\mathrm{O}$ pensamento identificatório teria, por fim, como propósito, evitar aquilo que lhe é desprazeroso e obter prazer ao transformar o que antes era um objeto externo estranho e assustador em algo familiar e que possa ser usufruído, de algum modo, pela criança.

Dessa forma, é sobre a aquisição do sentido de realidade que debruçamos nossa atenção, dentre aquilo sobre o que versam as propostas teóricas da autora. Num primeiro momento, a atribuição de sentido e assimilação de objetos é extremamente egocêntrica e limitada, e só depois se torna mais complexa. A. Balint, no entanto, vai ressaltar que essa imagem notável do mundo compreendido a partir do nosso ego-prazer (pré-"realidade") persiste para sempre no nosso inconsciente e acaba por ser a responsável por estabelecer a base de um antropomorfismo (egocêntrico) que sempre estará por trás até mesmo dos pensamentos mais científicos e objetivos. A. Balint vai sustentar que, naturalmente, o pensamento identificatório teria sua constituição muito atrelada ao narcisismo - mas se considerarmos que o narcisismo nunca se estende para além do próprio ego do sujeito, há de concebermos a identificação como a ponte pela qual o sujeito pode passar de um "autoamor" (embora também relacionado com o meio externo) a um "amor-realidade" (amor objetal com senso de realidade).

$\mathrm{O}$ artigo se estende discutindo particularidades, de um ponto de vista prático e observável, da relação entre a criança e seus educadores, representativos do mundo externo. Inspirada por Ferenczi, a autora o referencia em algumas passagens do texto - numa primeira delas, com o intuito de pensarmos sobre a constituição do superego, A. Balint retoma uma afirmação do autor postulada a partir de análises feitas com adultos: o superego, instância que a princípio 
tem também como objetivo auxiliar na adaptação do sujeito ao mundo externo, pode, mais tarde, interferir e inclusive se colocar como obstáculo para outras adaptações subsequentes. Para Ferenczi, a cisão do ego (que resultará no desenvolvimento do superego) como resultado de identificações com uma proibição também irá causar sérios danos ao próprio ego.

Sabemos que Ferenczi irá trabalhar ainda mais suas ideias acerca do desenvolvimento infantil intimamente relacionado às relações objetais no famigerado artigo sobre a "confusão de línguas" entre a criança e o adulto, entre a linguagem da ternura e a linguagem da paixão (Ferenczi, 1933/2012c); sua reconsideração acerca da teoria do trauma ao considerá-lo também em sua instância real será também toda discutida a partir da identificação da criança com o agressor e, consequentemente, da introjeção da culpa daquele - esta, intolerável para a criança e parte essencial, com a própria ação da violência e do desmentido, da constituição do trauma. Não nos deteremos, porém, nesse ponto em específico, mas seguiremos nossa corrente de pensamento em direção à ideia das relações objetais primárias.

Em “Amor pela mãe e amor materno" (A. Balint, 1939/1952), encontramos um texto muito mais teórico que, no entanto, não deixa de ser permeado também por inúmeros exemplos clínicos. Esse tipo de escrita demonstra a implicação dos analistas húngaros com a "aplicabilidade" da psicanálise, com sua experiência prática e uso terapêutico. Não somente os exemplos evidenciam isso: o objetivo dos textos apresentados sempre parte de uma constatação prática e, justamente por isso, se debruçam sobre problemas até então pouco explorados e que dizem respeito a uma demanda usual. A autora destacaria, por fim, a inovação presente em seu artigo relacionada à síntese de muitas ideias originais que estavam em discussão e que, ali, apareceriam organizadas e reconsideradas - mais uma razão para termos escolhido este como estudo representativo de um pensamento mais "coletivo" do grupo húngaro.

A. Balint nos diz, logo no início do estudo, que a psicanálise sempre teve um interesse especial pela relação mãe-bebê, mas a importância de se pensar mais a fundo tal vinculação veio a partir de constatações clínicas: regularmente, era necessário voltar-se ao período pré-edípico a fim de se refletir sobre ou explicar algum fenômeno prático. Assim, por ser a relação mãe-bebê a primeira relação objetal da criança, fica evidenciada a importância de investigá-la detidamente, desde seus "tempos nebulosos, quando as fronteiras 
do ego e do mundo externo fundem-se umas às outras" (A. Balint, 1939/1952, p. 109, tradução nossa).

A autora, no entanto, já trataria como uma relação objetal arcaica a estabelecida pela criança para com sua mãe, desde os primórdios. Ao citar exemplos clínicos distintos de pacientes que demonstravam, já adultos, exigências análogas às que uma criança tem com relação à sua mãe, A. Balint vai discorrer sobre essa configuração vincular infantil: não a considerará narcísica porque é perceptível que o amor é fortemente direcionado à mãe por parte da criança numa demanda pelo seu amor; tampouco chamará de amor objetal passivo, por conta da atividade nesse investimento libidinal ao objeto amado. Considera, portanto, uma relação dual, e não um posicionamento passivo e narcísico do bebê.

Propõe, por fim, considerar egoísmo ingênuo essa maneira arcaica de amar que originalmente se direciona à mãe. $\mathrm{O}$ que o bebê espera é uma espécie de "amor gratuito" desse objeto (mãe), já que sua falta de senso de realidade no amor o impediria (ingenuamente) de considerar outros interesses, libidinais e egoicos, presentes no objeto. A autora constataria esse tipo de funcionamento num certo número de fenômenos transferenciais que apareceriam independentemente do caso, da demanda ou da idade do paciente - inclusive em análises didáticas. Assim como discutido no artigo anterior (A. Balint, 1943), muitos "resquícios" de nosso funcionamento arcaico e mais narcísico perdurariam no inconsciente e influenciariam nossa vida ulterior - isso não apareceria, necessariamente, como uma psicopatologia, mas estaria presente em qualquer pessoa "saudável". É uma parte fundamental do nosso desenvolvimento como sujeitos, e ainda se faz presente no inconsciente (por excelência, atemporal), influenciando até mesmo nossas ideias e pensamentos mais "objetivos" - há sempre uma sobra desse amor infantil.

Em contrapartida, A. Balint se propõe a pensar, a seguir, o "amor materno", também caracterizado como sendo essencialmente libidinal. Os exemplos que a autora busca, agora, para ilustrar a relação que a mãe estabelece com a sua cria, convergem para estudos de caráter mais "antropológicos" - principalmente em uma das pesquisas de Roheim, mas também pautados nas formulações de Ferenczi em Thalassa (Ferenczi, 1924/2012b). Mas o que interessa para A. Balint é a configuração da sociedade moderna - aqui, diz ser plausível compreendermos, na maioria dos casos, o bebê que nasce como a realização de desejos instintivos de sua mãe. Essas demandas 
"instintivas" seriam satisfeitas pela mulher somente com a existência/ ajuda de seu bebê e, portanto, também se torna extremamente prazeroso para a mãe a vivência próxima à sua prole. A autora conclui: "Amor materno é a contraparte quase perfeita do amor pela mãe. Portanto, assim como a mãe é para a criança, a criança também é para a mãe um objeto de gratificação" (A. Balint, 1939/1952, p. 120, tradução nossa).

A. Balint está se referindo, aqui, ao que chama de "maternidade instintiva" (contraposta ao que seria uma "maternidade civilizada") e trata, desse modo, dos desejos e instintos naturais da mãe. O egoísmo ingênuo referido há pouco é possibilitado por uma espécie de interdependência biológica entre mãe e bebê; no entanto, ele não perduraria por muito tempo por conta dos conflitos ocasionados pelo desenvolvimento da civilização - o que acontece, gradativamente, é uma tentativa de resolução dessa "perturbação" no egoísmo ingênuo a partir da aquisição, por parte do bebê, do senso de realidade (sobreposto à vida emocional).

A autora nos fala, afinal, de um desenvolvimento dos modos de amar que parte de um primeiro momento (relação objetal arcaica sem senso de realidade) a outras formas mais socialmente elevadas, que derivariam de nossa adaptação à realidade; refere-se, aqui, às formas de amor, e não de gratificação/satisfação. Ao discorrer sobre a aquisição do sentido de realidade, sobre a entrada no social, A. Balint retoma a ideia do autoerotismo e sua função: no entanto, é enfática em afirmar que não acredita que haja alguma fase da vida que seja dominada somente pelo autoerotismo.

O que defende, aqui, é a ideia de que a dissolução da interdependência instintiva entre mãe e bebê vai interferir no funcionamento autoerótico da criança - e aqui, propriamente, começaria o papel "psicológico" do autoerotismo, já que assumiria uma importante função como satisfação substitutiva e tornar-se-ia a base do narcisismo secundário. A "quebra" da harmonia infantil resultaria nesse tipo de configuração, e quanto mais cedo isso acontece, mais cedo o autoerotismo assume esse papel.

Vale salientar que A. Balint defende que essa não seria uma regressão a um estado anterior denominado “autoerótico", já que o apego à mãe e $\mathrm{o}$ autoerotismo existiriam simultaneamente, num equilíbrio. O que aconteceria, após o abalo dessa relação harmônica e do decréscimo do egoísmo ingênuo é uma diferenciação mais aparente e perceptível para o bebê, que antes mal distinguia uma coisa da outra. O autoerotismo, portanto, surgiria quando o mundo dos objetos falha em oferecer satisfação ao sujeito - é um meio natural de se obter algum conforto (e só se tornaria psicopatológico caso extremamente sobrecarregado). Por outro lado, a sobrecarga das relações objetais em detrimento de uma supressão significativa das 
atividades autoeróticas pode, também, ocasionar comportamentos patológicos relacionados a uma grande dependência do outro, do externo. A. Balint, então, afirma que há, em cada idade, uma disposição ideal entre o autoerotismo e as relações objetais, e o equilíbrio (elástico) dentre as frustrações ocasionadas por um ou outro seria o responsável pelo desenvolvimento do senso de realidade no sujeito.

De acordo com Benedek (1993), o desenvolvimento do senso de realidade, estudado a partir das fases maturacionais do bebê, no famoso texto de Ferenczi (Ferenczi, 1913/2012a) caminhava paralelamente às discussões sobre a natureza do sintoma e sua relação com o estágio de desenvolvimento do sujeito (nível de fixação da libido e mecanismo de defesa usado na formação de sintoma, fixados num ponto do desenvolvimento do ego): esse estudo seria central para os trabalhos vindouros acerca das relações objetais mais arcaicas - como vimos em A. Balint, mas também em autores que ganhariam grande reconhecimento pela história psicanalítica, como Melanie Klein. Logo discutiremos o quanto a Escola Húngara de Psicanálise teria influenciado diretamente muitos dos teóricos da Escola Britânica, principalmente aqueles que representam o chamado "grupo independente" (ou "grupo da borda"), como M. Balint e Winnicott.

M. Balint seria o responsável por amadurecer e sintetizar, teoricamente, a ideia de uma relação objetal primária, que indiretamente já circundava alguns textos de outros autores húngaros. Em “A falha básica” (M. Balint, 1968/1993), publicado em 1968, o autor retomaria todas as suas propostas teóricas das últimas décadas em alguns capítulos subdivididos por temas: nos primeiros, investe numa discussão conceitual acerca do seu conceito de "amor primário", formulado em contraponto à ideia do narcisismo primário proposto por Freud em alguns de seus artigos - as propostas de M. Balint, porém, já vinham sendo desenvolvidas desde seus primeiros textos, tendo sua principal discussão em "Estados precoces de desenvolvimento do Ego: amor objetal primário”, de 1937 (M. Balint, 1952). $\mathrm{O}$ autor apontaria uma série de contradições e incoerências sobre as ideias do narcisismo primário, destacando, principalmente, a inexistência de uma definição coesa referente a sua formulação e dinâmica. Chama a atenção, numa releitura da obra freudiana, para o fato do criador da psicanálise, por vezes, utilizar-se de noções próximas (porém, essencialmente diferentes) como se tratasse de um mesmo período ou um mesmo funcionamento: desse modo fala em autoerotismo primário, amor objetal primário e narcisismo primário como coincidentes, mas sem apontar suas contradições.

Em defesa do amor objetal primário, M. Balint ressalta os pontos teóricos nos quais Freud apresentaria uma ideia a seu respeito, mais para o início de suas formulações científicas, e o fato de não ter abandonado por inteiro essa ideia mesmo depois de tê-la praticamente substituído pela teoria de um narcisismo 
primário. Para o autor, Freud hesitaria em abandonar essa primeira perspectiva mesmo depois da proposta metapsicológica do narcisismo primário porque nunca deixou de ser um exímio observador clínico, e assim não abriria mão de constatações da prática clínica em simples favorecimento de uma teoria bem organizada, mas sem sustentação experimental. Essa é a linha pela qual também segue Balint: defende a ideia de que o narcisismo secundário é facilmente constatado e observável clinicamente, mas o mesmo não se poderia dizer do narcisismo primário (que seria, por fim, sempre secundário).

Esse posicionamento de M. Balint retoma e nos indica uma série de fatores que viemos discutindo ao longo do texto, característicos da Escola Húngara, mas vale ressaltar o fato de o autor privilegiar sempre aquilo que é da ordem prática, passível de observação, como fundamentação de um argumento teórico - desse modo, a teoria simplesmente especulativa, mesmo que lógica naquilo que postula, não ganharia tanto espaço se pouco condizente com uma constatação experimental.

M. Balint rebate todos os argumentos favoráveis à ideia de um narcisismo primário a partir de constatações clínicas em um capítulo específico (M. Balint, 1968/1993), trata dos fatos clínicos sobre o narcisismo e examina todos os aspectos salientados por Freud em "À guisa de uma introdução ao narcisismo"
(Freud, 1914/2004): encontra, em todos eles, pontos que comprovariam o narcisismo secundário e sua importância para uma série de configurações subjetivas nossas ao longo do desenvolvimento (a saber: tipo de escolha objetal, formação do ideal do ego, funcionamentos idealizados e/ ou onipotentes, dentre outros). Até mesmo a regressão aliada ao sono, representativa de um estado primeiro tido como narcísico, seria, para o autor, não simplesmente uma "retirada do mundo dos objetos", mas uma retirada para um espaço que ainda considera o "entorno": o adormecido não estaria verdadeiramente sozinho, mas partilharia seu sono com objetos bons e internos/introjetados, e ainda há algo com o que se relacionar.

A proposta de M. Balint para a "superação" das contradições teóricas oriundas da ideia de um narcisismo primário vem a partir de um novo conceito: o de amorprimário, que nada mais seria do que uma teoria da relação primária do bebê com o entorno. A defesa da existência de relações de objeto desde o nascimento, que, como já vimos, é também oriunda de trabalhos de Ferenczi e A. Balint, tem em sua fundamentação a ideia de uma mãe que mesmo quando considerada naquela unidade basilar com seu filho, já se diferenciaria dele, em algum sentido, e se portaria não só como um "ambiente" acolhedor, mas também como objeto para obtenção de prazer. A interdependência biológica entre mãe e filho ainda pode ser lida a partir 
das trocas libidinais, numa espécie de "bem-estar" mútuo, como nos disse A. Balint (1939/1952).

Tal preocupação dos húngaros para com essas fases mais primitivas da existência e do desenvolvimento infantil se justificaria pelas experiências clínicas e pela necessidade de compreensão e investigação mais apurada acerca do funcionamento mental em determinados casos. A noção de "amor primário", de M. Balint, pode explicar melhor muito da clínica contemporânea e das relações transferenciais, como especifica Moreau-Ricaud (2005): “. . . não só no tratamento de pacientes psicóticos, mas também no material pré-edipiano dos neuróticos: demanda de gratificações primitivas, ingênuas, inocentes, e as respostas tranquilas ou passionais à gratificação ou frustração pelo analista" (p. 98, grifos do autor).

A autora continua sua explanação retomando a ideia de que na fase de amor primário os protagonistas mãe e bebê são igualmente recompensados e satisfeitos em sua relação - se algo falta de um lado ou de outro, segundo M. Balint (1952), essas tensões da relação podem ocasionar desde distorções no ego em desenvolvimento da criança quanto fenômenos neuróticos na mãe. $\mathrm{O}$ autor discutirá tais implicações numa nova teoria que formularia anos mais tarde, a da "falha básica" (M. Balint, 1968/1993). Anos antes, em "Excitações ${ }^{1}$ e regressão" (M. Balint, 1959, tradução nossa), o autor apresentaria seus conceitos de filobatismo e ocnofilia, também formulados a partir do estudo das relações objetais. Como dois “extremos”, essas estruturas se refeririam a comportamentos dos sujeitos voltados à relação estabelecida com os objetos externos: enquanto no mundo ocnofílico o investimento do sujeito adere aos objetos emergentes (uma espécie de "adesividade") e introjeta-os, por considerá-los seguros e tranquilizadores (e, em contrapartida, por sentir-se perdido e inseguro sem a sustentação ou presença destes), no mundo filobático é o inverso que impera, com o sujeito superinvestindo suas próprias funções do ego a fim de manter-se sozinho com muito pouco ou mesmo sem auxílio de objetos (por julgá-los perigosos ou "traiçoeiros"). Tais dinâmicas seriam resultantes das primeiras experiências de estabelecimento de relação com o mundo externo. Essas ideias são desenvolvidas ainda mais sob a perspectiva do estudo da "falha básica" (uma deficiência na estrutura da personalidade dos sujeitos, numa fase bastante precoce da existência que visaria compensar algum tipo de desajustamento referente ao ambiente), aqui considerando as possibilidades de trabalho clínico com os dois tipos e prenunciando, por fim, a ideia 
de um "novo começo" (new beginning, ideia presente já nos textos ferenczianos, mas trabalhada melhor por M. Balint para se referir a uma possibilidade de reconsideração das relações objetais na clínica e, para isso, fazendo uso, inclusive, da regressão iminente que poderia surgir na transferência, tida como benigna).

A regressão, outro tema ardiloso e de difícil aceitação como fenômeno clínico que pode ser benéfico, também começa a ser abordada por Ferenczi nas suas últimas experimentações: este queria que a regressão deixasse de ser vista simplesmente como resistência e procurava a potencialidade inerente no seu funcionamento para favorecer o trabalho positivo com o paciente. M. Balint aprimoraria as ideias de Ferenczi, que não pôde concluir seus estudos e experimentações antes de morrer, ao reconhecer dois tipos básicos de regressão que poderiam surgir no setting terapêutico, a saber, uma do tipo maligna (negativa, essencialmente um obstáculo à evolução do caso) e outra do tipo benigna (que de fato poderia mesmo ajudar em reconsiderações basais do paciente, principalmente no que se referia às relações objetais primárias, num trabalho voltado às problemáticas pré-edípicas).

Segundo Figueiredo (2012), Balint recorre explicitamente ao que chama de "tradição ferencziana", representada também por Alice Balint e Imre Hermann, para discutir suas primeiras ideias acerca do amor primário: do último, especificamente, utiliza-se de inúmeras evidências constatadas sobre as relações objetais primordiais, analisando, ainda, as respostas saudáveis ou patológicas dadas pelos bebês a um objeto primário. Os estudos de Hermann, segundo M. Balint, eram incitados por uma investigação primordial: o desejo instintual por contato físico (assunto que também perpassava as relações clínicas das últimas experimentações de Ferenczi, nas quais, por vezes, havia a possibilidade de o paciente poder tocar o analista ou de ser tocado por ele). Hermann encontraria, em seus estudos da década de 1930, alguns pontos interessantes que se referiam a essa discussão: num deles, com psicologia comparativa e estudo dos primatas, constatava que os bebês macacos passavam alguns primeiros meses da vida extrauterina agarrados a suas mães; paralelamente, concluía em outro o quão cedo o bebê humano era forçado a se separar de sua própria mãe e as consequências disso - essa frustração da realidade, em nossa civilização, seria responsável pelo desenvolvimento de alguns comportamentos sintomáticos, como a posição de dormir, ações erotizadas referentes à sucção e manipulação e, por fim, aquela que

334 Estilos clin., São Paulo, v. 20, n. 2, mai./ago. 2015, 325-338. 
seria sua descoberta mais notável, uma tendência generalizada de agarrar-se em alguma coisa em momentos de ameaça ou perigo.

É a partir dessas constatações que se torna possível delinear, dentre os psicanalistas húngaros e suas propostas, uma identidade de grupo: o que mobilizava a atenção da Escola Húngara nas décadas de 1920 e 1930 muito tinha a ver com o período pré-edípico de desenvolvimento infantile, tendo a prática clínica como prioridade, chegava-se a constatações também teóricas sobre o funcionamento mental. A formulação de M. Balint sobre o amor primário, por exemplo, não é uma concepção teórica individual, mas antes a síntese de toda uma preocupação compartilhada pela Escola Húngara, a consolidação de um trabalho coletivo que teve origem bem antes de sua conceituação e amadureceu até culminar na noção proferida pelo autor, provavelmente influenciada, ao longo dos anos, também por discussões conceituais em encontros e reuniões, eventos de psicanálise, partilha de experiências e pontos de vista entre os membros da Sociedade Húngara.

\section{Considerações finais}

Os psicanalistas empreendiam esforços que, em última instância, tinham como objetivo desenvolver e esclarecer melhor os pontos que até então se mostravam vagos, pouco estudados, mas que apareciam como frequentes entre as demandas terapêuticas. É por isso que se torna fácil conceber o vínculo estabelecido entre a teoria das relaçoos objetais primárias e os fenômenos referentes à dinâmica transferencial, no setting clínico - a primeira influenciava diretamente o que ocorria na segunda, e era necessário considerar essas mudanças também no modo de se conceber os atendimentos, pensar os objetivos da terapia e atentar aos alcances e limites da prática da psicanálise.

Assumindo, por fim, um posicionamento de defesa das relações objetais como primordiais e visando ainda destacar sua natureza libidinosa, principalmente no que concerne à troca de prazeres experimentada na relação mãe-bebê, M. Balint insistia também no quão significativas estas seriam para todo o funcionamento psíquico ulterior do sujeito: incluindo também, portanto, o adoecimento psíquico.

Sem perder de vista a discussão acerca dos fenômenos da transferência e contratransferência, que também entram com força no bojo das problematizações da Escola Húngara (em especial a partir dos estudos e posteriormente das experimentações de Ferenczi), logo percebe-se o quanto esses estudos sobre as relações objetais primárias embasariam discussões ulteriores sobre as mudanças e reconsiderações técnicas, necessárias como perspectiva de ampliação da prática da psicanálise - acarretariam em reconsiderações e ampliações no 
que concerne à técnica psicanalítica e às mudanças expressas em alguns de seus aspectos, a fim de se poder atender a demandas "diferenciadas" das "neuroses clássicas" inseridas na clínica. Não só consideraríamos, ainda, o que poderiam ser nomeadas "patologias narcísicas" ou "pré-edípicas" e que exigiriam de fato uma mudança de postura por parte do terapeuta inserido na dinâmica transferencial, mas também algumas questões básicas que perpassariam qualquer tipo de atendimento clínico concernentes às demandas clínicas contemporâneas. As mudanças consideradas pelos húngaros implicariam em novas possibilidades de leitura e abordagem dos casos, e ainda se refletiriam, naquela época, na proposta diferenciada de "formação analítica" da Sociedade Húngara de Psicanálise, singular e diferente daquela adotada em Berlim, que traria indiretamente consigo a exigência de uma postura mais ética e implicada na relação terapêutica por parte do candidato a psicanalista. É sobre ética, responsabilidade e implicação pessoal por parte do analista que podemos compreender muitos dos estudos contemporâneos desta perspectiva realizados no país, por exemplo, que, geralmente, são referidas como "ética do cuidado" (Figueiredo, 2009; Bouwman, 2011) e dizem de uma "presença sensível" (Kupermann, 2008), uma "psicanálise a duas pessoas" (Landa, 2010), de uma clínica "po-ética" (Safra, 2004) ou ainda, como compreende Landa (1999,
2005, 2010) a partir de Abraham e Torok no lidar com a clínica, com os pacientes e com a própria psicanálise como sendo "poesia e autocriação". Todos se referem a essa "psicanálise intersubjetiva" que resgata, em sua proposta, a essencialidade das relações objetais como primordiais ao desenvolvimento subjetivo.

THE PRIMACY OF OBJECT RELATIONS IN THE SUBJECTIVE DEVELOPMENT SET IN THE STUDIES OF THE HUNGARIAN SCHOOL OF PSYCHOANALYSIS: A HISTORICAL PERSPECTIVE

\section{Abstract}

The purpose of this article is to discuss some of the first studies focused on understanding primary object relations. To this end, attention turns to the Hungarian School of Psychoanalysis, a group of psychoanalysts of the first generations of the psychoanalytic movement led by Sándor Ferenczi and responsible for quite unique avant-garde studies regarding the psychoanalytic theory of subjective development, clinical practice and psychoanalytic technique. From a historical perspective, these studies were pioneer in considering the primary relationship between mother and baby - they substantiated and influenced big names and schools of psychoanalysis.

Index terms: psychoanalysis; the bistory of psychoanalysis; object relations; Hungarian School.

LA PRIMACIA DE LAS RELACIONES OBJETALES EN EL DESARROLLO SUBJETIVO EN LOS ESTUDIOS DE LA ESCUELA HÚNGARA DE PSICOANÁLISIS: UNA PERSPECTIVA HISTÓRICA

\section{Resumen}

El objetivo de este artículo es discutir algunos de los primeros estudios para la comprensión de las relaciones objetales primarias. Por ello, la atención se dirige a la Escuela Húngara de Psicoanálisis, grupo de psicoanalistas de las primeras generaciones del movimiento 
psicoanalitico, encabezado por Sándor Ferenczi, responsable de estudios de vanguardia, originales, a respecto de la teoría psicoanalitica del desarrollo subjetivo, de las prácticas clínicas y de la técnica psicoanalítica. Desde una perspectiva histórica, estos estudios han sido pioneros en considerar la relación primaria entre la madre y el bebé - al fundamentar e influenciar grandes pensadores y escuelas de psicoanálisis posteriores.

Palabras clave: psicoanálisis; historia del psicoanálisis; relaciones objetales; Escuela Húngara.

\section{REFERÊNCIAS}

Balint, A. (1943). Identification. International Journal of Psychoanalysis, (24), 97-107.

Balint, A. (1952). Love for the mother and mother love. In: M. Balint, Primary love and psycho-analytic technique. Londres, Inglaterra: The Hogarth Press. (Trabalho original publicado em 1939).

Balint, M. (1952). Primary love and psycho-analytic technique. Londres, Inglaterra: The Hogarth Press.

Balint, M. (1959). Thrills and regression. Nova York, NY: International Universities Press.

Balint, M. (1993). A falha básica: aspectos terapêuticos da regressão (F. F. Settineri, trad.). Porto Alegre, RS: Artes Médicas. (Trabalho original publicado em 1968).

Benedek, L. (1993). What can we learn from Ferenczi today? In L. Aron, \& A. Harris. The legacy of Sándor Ferenczi. Hillsdale, NJ: Analytic Press.

Bouwman, M. W. (2011). A ética do cuidaz do na clínica psicanalítica. Estudos de Psicanálise, (36), 109-116.

Ferenczi, S. (2012a). O desenvolvimento do sentido de realidade e seus estágios. In $\mathrm{S}$. Ferenczi, Psicanálise II (A. Cabral, trad.). São Paulo, SP: WMF Martins Fontes. (Trabalho original publicado em 1913)

Ferenczi, S. (2012b). Thalassa. In S. Ferenczi. Psicanálise III (A. Cabral, trad.). São Paulo, SP: WMF Martins Fontes. (Trabalho original publicado em 1924)

Ferenczi, S. (2012c). Confusão de língua entre os adultos e a criança. In S. Ferenczi. 
Psicanálise IV (A. Cabral, trad.). Sáo Paulo, SP: WMF Martins Fontes. (Trabalho original publicado em 1933)

Figueiredo, L. C. (2009). As diversas faces do cuidar: novos ensaios de psicanálise contemporânea. São Paulo, SP: Escuta.

Figueiredo, L. C. (2012). Balint em sete liçōes. São Paulo, SP: Escuta.

Freud, S. (2004). À guisa de introdução ao narcisismo. In S. Freud. Escritos sobre a psicologia do inconsciente (L. A. Hanns, trad.). Rio de Janeiro, RJ: Imago. (Trabalho original publicado em 1914)

Kupermann, D. (2008). Presença sensivel: cuidado e criaçâo na clínica psicanalitica. Rio de Janeiro, RJ: Civilização Brasileira.

Landa, F. (1999). Ensaio sobre a criaçâo teórica em psicanálise: de Ferenczi a Nicolas Abraham e Maria Torok. São Paulo, SP: UNESP/FAPESP.
Landa, F. (2005). Existe uma teoria de formação de psicanalista a partir de uma perspectiva ferencziana? Tempo Psicanalítico, (37), 191-206.

Landa, F. (2010). A poesia e a clínica propriamente psicanalítica. Psicologia USP, 21(3), 557-565.

Moreau-Ricaud, M. (2005). Amor primário. In A. Mijolla (Dir.), Dicionário internacional da psicanálise (A. Cabral, trad.). Rio de Janeiro, RJ: Imago.

Safra, G. (2004). A Pó-ética na clínica contemporânea. Aparecida, SP: Ideias \& Letras.

\section{NOTA}

1. No original, "thrills", substantivo que pode ser traduzido como emoção, estímulo ou excitação, referindo-se a um sentimento súbito de excitação e prazer, mas que também causaria vertigem ou atordoamento.

mmcasadore@yahoo.com.br

Rua Benedito Lutti, 626 19802-060 - Assis - SP - Brasil.

frahas@assis.unesp.br

Avenida Dom Antonio, 2100 19806-900 - Assis - SP - Brasil.

Recebido em fevereiro/2015. Aceito em julho/2015. 